\title{
Abu Dhabi's New Urban Islands and Shorefront Development
}

\author{
Mohamed El Amrousi ${ }^{1, *}$, and Mohamed Elhakeem ${ }^{2}$ \\ ${ }^{1}$ Department of Architecture, Abu Dhabi University, P.O. Box 59911, UAE \\ ${ }^{2}$ Department of Civil Engineering, Abu Dhabi University, P.O. Box 59911, UAE
}

\begin{abstract}
Abu Dhabi is in the process of urbanizing a group of Islands that surround its northern and eastern coastlines. Al-Lulu, Al-Saadiyat, AlMaryah, Al-Reem and Yas Islands are all new urban enclaves that were desert islands and marshlands yet, have been developed over the past decade to urban islands that include epic and entertainment centres such as the Abu Dhabi Louvre, Guggenheim Museum, Ferrari World, NYU Abu Dhabi, the Paris Sorbonne Abu Dhabi in addition to iconic and exclusive waterfront residential units. These new islands re-brand the image of the main archipelago of Abu Dhabi that for decades retained a grid street pattern and pragmatic concrete blocks created in the late 1970s. The new urban islands transform Abu Dhabi's image into a multinational modern Arab city seeking to become part of the global city network. Abu Dhabi's new urban islands also act as breakwaters that protect the main archipelago's coastline from erosion resulting from tidal change, because they are designed to include concrete and stone breakwater barriers. This paper represents a cross-disciplinary research between Civil Engineering and Architecture Departments in an attempt to explore the emerging infrastructure and urban expansion of Abu Dhabi from a multi-disciplinary perspective. We also highlight through simulating the effect of breakwaters on wave heights two scenarios for Al-Lulu Island the importance of these new barrier Islands on the urban expansion of Abu Dhabi.
\end{abstract}

\section{Introduction}

Abu Dhabi is reshaping much of its coastline through new urban developments and hence changing its image from a city known for its conservative local community to one that is more attractive to expatriate residents. This is achieved through the creation of a new group of urban islands that reshape desert islands and existing marshlands connecting them to the mainland through a series of bridges and supporting them with the necessary infrastructure. These islands also act as protection for the coastline of the main archipelago because they entail the infrastructure through breakwaters and marinas to create barrier islands. These new urban islands are designed to exhibit the richness of Abu Dhabi as the Capital of an oil rich State, this is manifested through the construction of mega museums, iconic buildings and clustered epic centers to create new public spaces. The transition of

\footnotetext{
*Corresponding author: Mohamed.amrousi@adu.ac.ae
} 
Abu Dhabi from a transit city, which till the 1970's exhibited characteristics of tribal conservatism and remoteness from modernity represents a new phase in the city's urban expansion, infrastructure and socio-cultural establishment (Fig. 1). Abu Dhabi is an archipelago connected to the mainland via two bridges, therefore many of its conservative geographies can be understood if associated with traditional Island communities. This was especially visible in its architecture, urban fabric shaped along modernist design ideologies, traditional community, practices and regulations. In the last decade Abu Dhabi has announced is 2030 Vision that advocates plans to become more open internationally through iconic mega projects and an infrastructure and new spaces of entertainment. Abu Dhabi's urban expansion plan includes a gentrification of the existing building stock in the living city mainly the Down Town area and its Corniche. As its main waterfront promenade the Corniche of Abu Dhabi is undergoing major reconstruction projects that aim to improve its public spaces and communal spaces of gathering. This is exhibited through the creation of public beaches connected to the Downtown via tunnels, the municipality is also creating new entertainment hubs along the Corniche that include cafes, spaces of gathering, centers for sports activities, special lanes for jogging and cycling and shaded seating (Fig. 2). These are all initiatives that are essential in order to maintain the competitiveness of the old downtown especially when juxtaposed with the new upscale facilities emerging on its new urban islands. All major investments are supported by Abu Dhabi's royal family and aim to support international initiatives to improve the quality of life in the city and to transform the city from a transit one to one of long term residency and multinational investment. Part of the internationalization of Abu Dhabi includes Sassaki's plan for the gentrification of the old Port-Mina Zayed that has commenced to transform the old warehouses and shipyards into contemporary museums, and cultural facilities. Sassaki's design incorporates the new Abu Dhabi Media Company headquarters which will be sustained by hotels, retail, and high rise residential units overviewing the Corniche. These visible changes in Abu Dhabi that aim for communal wellness and its transformation to a healthy city are witnessed by its residents especially the new buildings emerging along its coastline overlooking its newly created estuaries that separate between the mainland and its urban Islands. Abu Dhabi's ambitious program of shorefront urban development's aim to serve a larger economic agenda by increasing demand for construction sector services and supplementary investments related to tourism, entertainment and business entrepreneurship. This paper is divided into two sections that complement each other and highlight the crossdisciplinary venues of research possible between architecture and Civil Engineering. The first part addresses Abu Dhabi's shorefront expansion in the form of urban islands that also act as breakwater barrier to protect the mainland/archipelago. The second studies via simulation the shorefront protection system that accompanies the creation of these new urban islands using Lulu Island as a case study.
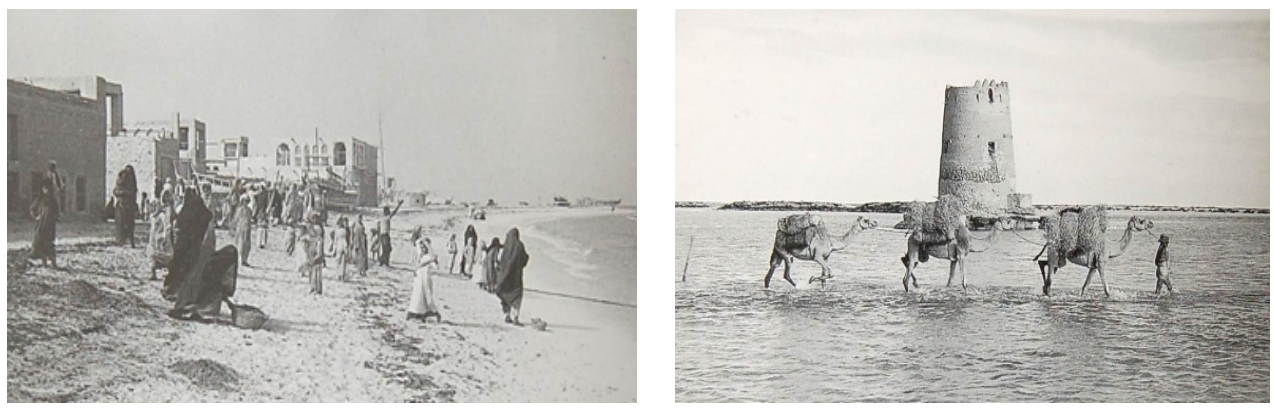

Fig. 1. Abu Dhabi 1948-1950. 

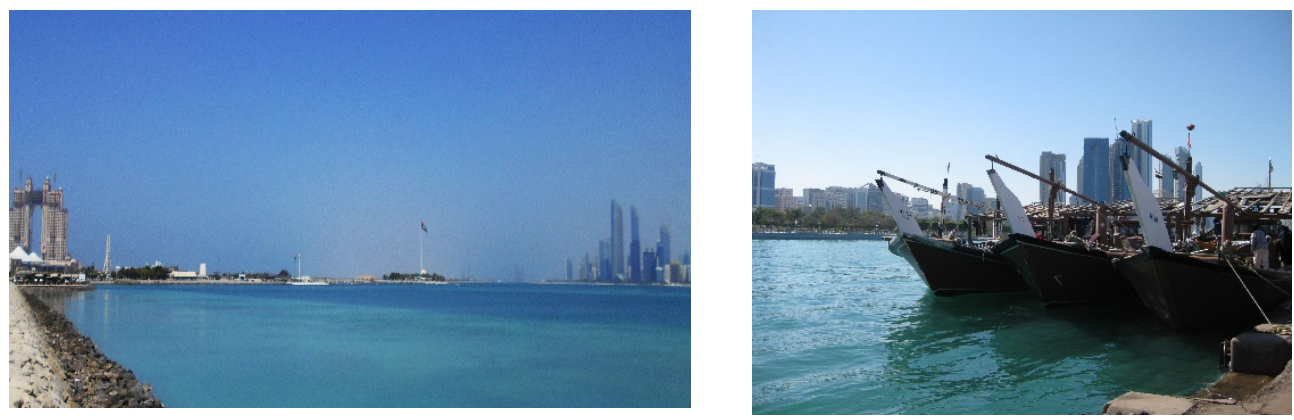

Fig. 2. Abu Dhabi; Marina, the Corniche and Old Port-Al-Mina.

\section{Abu Dhabi's urban islands}

Al-Lulu, Al-Saadiyat, Al-Maryah, Al-Reem and Yas Islands represent the new urban expansion to the main archipelago of Abu Dhabi, in their planning which is part of the Abu Dhabi 2030 Vision, reducing the effect of marginalization that occurs to old urban centers once new ones appear has been taken into consideration. This is achieved through the visual and physical connectivity infrastructure represented by successive bridges and tunnels, and waterfront promenades that do not obscure the visibility between new and existing. This link is further cemented by signs stating the names of these islands, thereby reducing the effect of marginalization of the old created by the vividness of the new monumental and upscale mega projects separated by water canals. Al-Saadiyat, Al-Maryah, Al-Reem and Yas Islands have evolved with a cultural and environmental perception in mind in that they offer new venues for local and expatriate residents of the city to enjoy international museums, high-end hotels and residences without leaving their homeland [1]. This development is also paralleled with an aspect of environmental sustainability through the plantation of mangrove trees in marsh lands and lagoons created in between these islands. Although the phenomena of creating artificial islands is one that is spreading though the Gulf States, there are different planning ideologies even within the UAE, for example Dubai's artificial Islands differ from those of Abu Dhabi. In terms of construction the Palm Islands in Dubai's reflect on its urban agenda to retain its status as a Star city in the Gulf region. Visual connectivity is reduced to provide privacy its residents. In terms of construction they are fully artificial, created by dredging and backfilling to shape a Palm like waterfront real-estate development that is only visible from top-down aerial views. The Palm (Jumeirah) is protected by a concrete barrier that is in the form of a crescent creating finger islands known as the 'Palm fronds' were canal-estate development offers its residents high-end villas and private beaches, while public or semi-private beaches are scarce on Palm Jumeirah - the most complete of the Palm islands trilogy. Dubai's 'World Islands' further support its policy for dredging and backfilling parts of its waterfronts that are even less connected to its mainland creating a core/periphery relationship were the periphery emphasizes the concept of 'Fantasy Islands'. In Abu Dhabi the new urban islands are very real and accessible to all even though they do offer a degree of exclusivity manifested through their building typologies. The shapes of Abu Dhabi's islands with their smooth coastlines and narrow estuaries created between them highlights the duality of their role as barrier and urban islands that support the image of Abu Dhabi as an emerging modern city with cultural hubs and clustered epic and entertainment centers open to all its residents [2].

Abu Dhabi's new urban islands manifested the need for Abu Dhabi to reshape its image through new forms of real-estate development warranted by an increase in the diversity of 
socio-cultural communities seeking to reside and invest in Abu Dhabi. Saadiyat has a visible Cultural clustering with projects that have acclaimed international visibility like the Desert Louvre by Jean Nouvel, the Abu Dhabi Guggenheim by Frank Gehry, and the forthcoming Zayed National Museum are all mega projects indicative of the fact that pubic construction projects, are likely to remain a key driver of the construction sector and the economy as a whole [3]. Al-Maryah and Al-Reem Islands were planned to represent the corporate image of the Abu Dhabi through the creation of a new Central Business District, this is especially evident in the multi-scaled and inter-connected group of buildings on AlReem Island known as the Gate Towers that is developed by Sorouh. The Abu Dhabi Gate Towers, with their 3533 residential units in four towers as well as retail and leisure facilities that pay tribute to Singapore's Marina Bay Sands development designed by Moshe Safdie, and represent an example of branding of the spaces created by globalization. Accompanying this phenomena there is also a sense of sameness or creation of architectural facsimiles that accompany the globalization of space. The creation of clustered/exclusive residences along newly formulated shorelines, and creating cities that share spaces of sameness is a phenomenon that is being witnessed in the network of global cities such as Dubai, Doha, Singapore and Hong Kong etc., and can be understood as an expansion inscribed by the emergence of new social groups and expatriate communities. Abu Dhabi's interest to seek a share of the capital investment worldwide inscribed on its planners acceptance of changing its initial low profile fabric to one that is branded through monumentality and mega projects [4]. Al-Dar and Sorouh have been merged to create a mega construction company that is able to become a major player as master developer behind Shams Abu Dhabi, a project that aims to create a mixture of commercial, retail and residential space, including the 74-storey Sky Tower and 65- story Sun Tower. Other mega projects are represented by Yas Mall that is currently the largest mall in Abu Dhabi with its 235,000 sq. meters of shopping space and 370 stores 60 of which are international restaurants (a major change for a city that has retained for decades a conservative tribal culture), Yas Marina adds new multi-national public space to Abu Dhabi in terms of waterfront entertainment projects that focus on public spaces of gathering along the Marina shorefront with pedestrian paths that are specifically designed for public uses like a jogging, walking and cycling etc. Here there is no simple demarcation between public and private waterfront landscapes [5]. Yas Island highlights the emergence of high-end clusters of epic and entertainment Centers on a mega scale such as the Ferrari World, Viceroy Hotel and Yas Mall that could have created a juxtaposition of old and new is manifested by the modernist 1970's design of buildings on the mainland and its new offshore developments. Abu Dhabi new expansion via urban islands, changes in the Downtown and Mina areas represent a challenge for urban planners and designers as they attempt to balance between retaining cultural values and the conservative community of the oil rich State and the sociocultural changes inevitable through the emergence of spaces of entertainment and epic centers in order to avoid the pitfall of loss of identity and marginalization of some communities within the existing/living city. In the Abu Dhabi 2030 Vision retention of Emirati identity and cultural values is highlighted, as special districts for nationals are planned in parallel to the emerging iconic architectures in Abu Dhabi's new shorefront urban expansion (Fig. 3). 

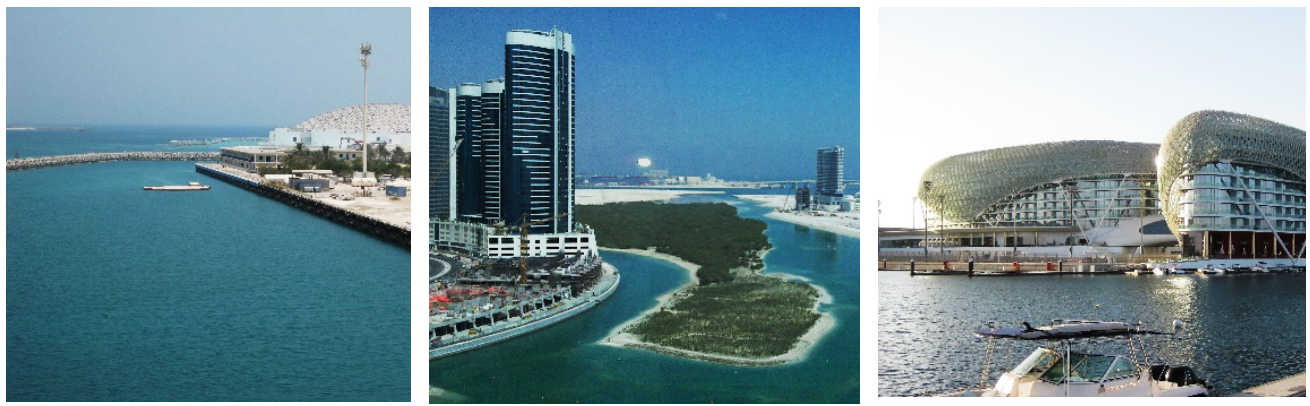

Fig. 3. Al-Saadiyat-Abu Dhabi Louvre-Al-Reem Islands-Yas Island Marina.

\section{Globalization and urban-island development}

The common perception of Islands are usually associated with an image of spaces that escape modernity via isolation spaces that offer its visitors a utopian experience that is embedded in the traditional attire of their communities. However, Al-Saadiyat, Al-Reem Al-Maryah and Yas Islands reflect an alternative perception of space, one that is shaped by new building morphologies that create spaces of emerging epic centers of culture and leisure, this heavy investment in the construction industry manifests Abu Dhabi's interest to emerge on the map of global cities through State sponsored mega-projects. However, Abu Dhabi's investments are not dominated by an attire of exclusivity, they also highlight the importance of culture as main theme, exemplified by the Construction of the Abu Dhabi Louvre, the Abu Dhabi Guggenheim, and the new Sheikh Zayed National Museum that aim to brand Abu Dhabi as a city that values culture and heritage. While there is a clear paradigm shift in Abu Dhabi's urban strategies, which for decades aimed to preserve a tribal-social structure through the exclusion of entertainment and leisure centers, many of the pitfalls of Dubai's rapid urbanization have been avoided especially urban fragmentation. Much has been done to avoid social segregation and to connect the mainland through several bridges and tunnels to the newly developed urban islands of Abu Dhabi. There still is a clear manifestation of global agendas that decontextualize regional-design criteria on both environmental and cultural levels, yet many of the cultural projects aim to create spaces and places of familiarity and interest for the local community and international investors. As outlined by Anna Gospodini, culture and leisure waterfront epic-centers created in Abu Dhabi correspond to manifest a process of urban renewal and generate new building typologies in the post-modern city. These are especially manifested through the adoption of brand names of in institutions of Culture such as the Guggenheim and Louvre, in education such as NYU and the Paris-Sorbonne and healthcare such as the Cleveland Clinic [6]. The global extent of artificial residential waterways created in the last decade highlights the degree of investment in infrastructure by the State and confirms a new interpretation of the modern city as a hybrid group of spaces that includes spaces of the living city and a new social structure created on the spaces of Abu Dhabi's urban which are somehow 'more real' as extensions of city spaces even though they are visually distinct through clear references to international counter structures. Nevertheless they cannot be considered as Peripheral to a Core rather a more upscale and exclusive version of the mainland represent constant evolution of the city [7].

Al-Saadiyat, Al-Maryah, Al-Reem and Yas Islands also manifest a transitional shift in perception of communities living in gulf/desert regions that may have been classified as tribal or conservative ones that adopt an attire and behaviors of new forms of universalism, created by spaces and a new genealogy of buildings. These communal paradigm shift is 
associated with the city image-branding created by the multiplication of massive structures built with corporate imagery, especially on Al-Reem and Al-Maryah Islands. All of Abu Dhabi's new islands reflect design criteria that caters to spaces mediation between the local residents and the expatriate community (with the exception of Al-Samaliyah Island that was created as an urban museum of local heritage). Despite growing competition for the niche in cultural and entertainment facilities Abu Dhabi's morphological development of AlReem Island embraces these economically high-risk ventures. As King outlines globalization, and shared interdependency have become a fact of life through which a global imaginary is becoming an environment and an identity [8]. This may offer an explanation for the simulacra of some of the international iconic buildings such as the Marina Bay Sands Towers and the Gate Towers of Abu Dhabi which both reflect the extensive use of glass facades in hot humid climates in addition to colossal scale and similarity of form. This combination of the spatial reproduction and re-enactment of narratives seeks to create a new image of becoming a global city through building typologies that serve to repackage the image of Abu Dhabi from a conventional Arab city to one that offers the potential of an International lifestyle.

\section{The shoreline protection system of Abu Dhabi's islands}

In this section of the study we evaluate the design of the current shore protection system of Abu Dhabi City Main Island. Two scenarios were simulated: scenario 1) Prior to 1970, where neither the breakwaters nor the Lulu Island was constructed (Fig. 4A); scenario 2) the shoreline condition after 2003, where Abu Dhabi City shoreline was reshaped and protected by the onshore and offshore breakwaters, and the Lulu Island (Fig. 4B). The Lulu Island assumed to provide additional protection to Abu Dhabi City shoreline by diffracting the wave energy. Another function of the Island was to hide the offshore breakwaters and to be used as a recreation area providing an aesthetic appeal from the shoreline. The Main Island is facing the Arabian Gulf from the north-west side and is exposed to continuous current wave action. Prior to 1970, where neither the breakwaters nor the Lulu Island was constructed (Fig. 4A), the waves were approaching Abu Dhabi City shoreline without any diffraction causing washout of the sand and hence beach erosion.
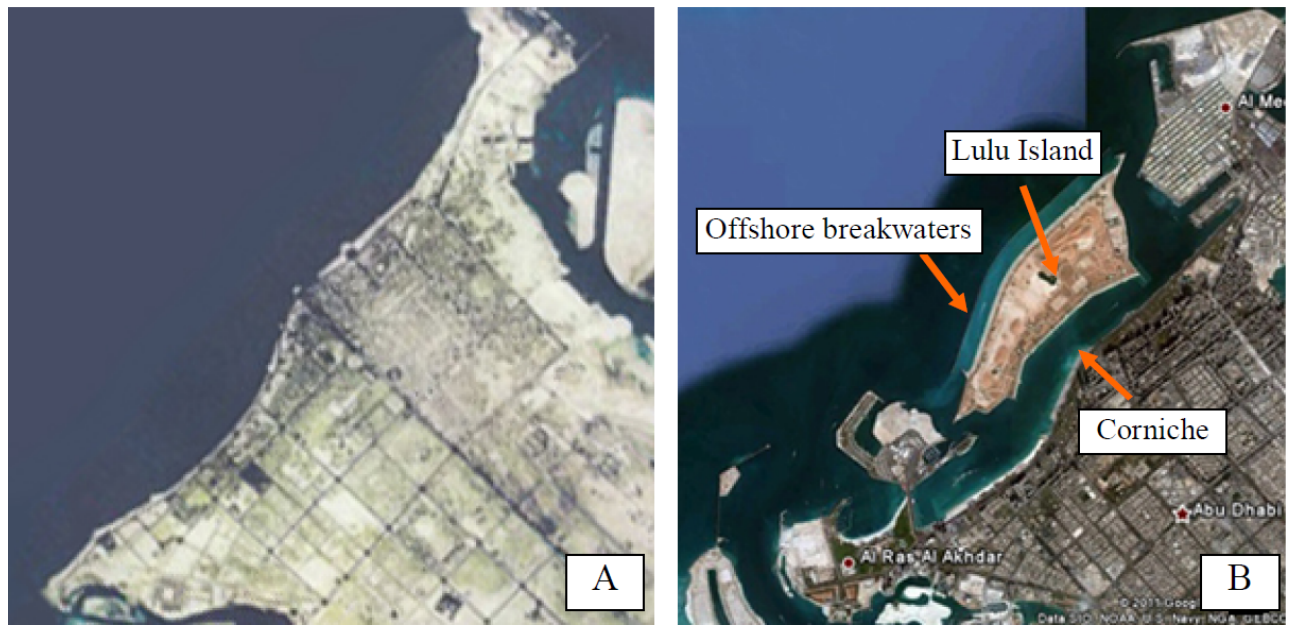

Fig. 4. Abu Dhabi City shoreline: A) prior to 1970; B) after 2003. 
In 2003, a shore protection system was developed on this side from the Main Island of Abu Dhabi City (Fig. 4B). The developing of the shore protection system of Abu Dhabi City Main Island went through three stages: 1) reshaping of the shoreline by degrading and damping huge amounts of natural sand; 2) constructing of onshore and offshore breakwaters; and 3) developing of the Lulu Island. Due to the complex geometry of Abu Dhabi City shoreline protection system, a 2D-hydrodynamic model was used in the evaluation of the design. The Costal Graphical Wave (CGWAVE) developed by the US Army Corps of Engineers [9-11] was used to simulate the wave characteristics when they approach the breakwaters and shoreline. The model was calibrated by matching the model wave outputs at the Um Al Dalkh Wave Station, located in the south-west of the model domain, with the measured values of the station. This was done iteratively by changing the wave height at the boundary until the simulated wave height at the station matches the measured value.

Two scenarios were simulated using CGWAVE: scenario 1) Abu Dhabi City shoreline prior to 1970, where neither the breakwaters nor the Lulu Island was constructed. Under this condition, the waves were approaching the shoreline without any diffraction causing washout of the sand and hence beach erosion. In this scenario, we have examined the tidal action in terms of wave height and water surface elevation; and scenario 2) Abu Dhabi City shoreline after 2003 representing the current shoreline condition, where the shoreline was reshaped and protected by onshore and offshore breakwaters, and the Lulu Island. The Lulu Island assumed to provide additional protection to Abu Dhabi City shoreline by diffracting the wave energy. In this scenario, we wanted to examine effectiveness of current shore protection system in providing sufficient protection to the Abu Dhabi City shoreline by damping the wave energy.

In the simulations, we have examined the tidal action in terms of wave height due to wind blowing from the west direction towards Abu Dhabi City shoreline. Fig. 5A shows CGWAVE simulations of scenario 1 for the wave height along Abu Dhabi City shoreline prior to 1970, where neither the breakwaters nor the Lulu Island was constructed.

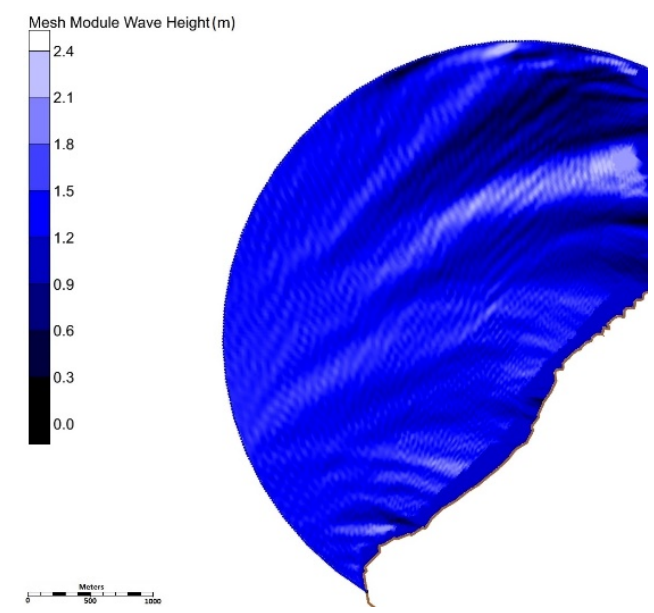

(A)

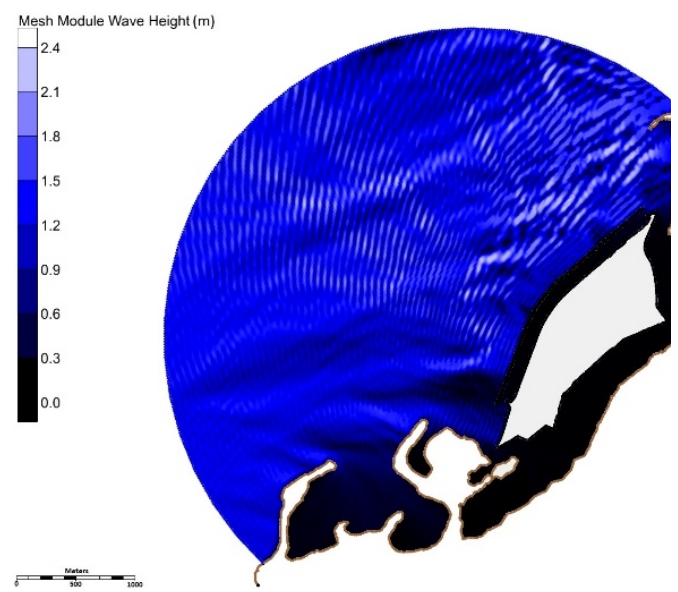

(B)

Fig. 5. Predicted wave height at Abu Dhabi City shoreline: (A) scenario 1; (B) scenario 2.

The figure show the simulation for it can be seen that the wave heights vary from 0.1 to $3.0 \mathrm{~m}$. Ocean waves lose part of their energy as they approach the shoreline, but the energy is still great enough for the wave to reach the shoreline at heights that allow them to cause 
beach erosion. Fig. 5A shows scenario 2 after 2003 representing the current shoreline condition, where the shoreline was reshaped and protected by onshore and offshore breakwaters, and the Lulu Island. It can be seen that the offshore breakwaters dissipate most of the ocean wave energy before they reach the Lulu Island and then the Island completely hinders the waves from reaching to the Abu Dhabi City shoreline. It is also evident that some areas behind the island are completely dead from any wave action due to the offshore breakwaters; the water is almost completely still. The wave heights along the shore and around the Lulu Island are almost zero as can be seen in Fig. 5B. Thus, the proposed design of the shore protection system was successful in controlling beach erosion and flooding by damping the wave energy.

\section{Conclusion}

Throughout this study we highlight the possibilities of cross-disciplinary research between architecture and Civil Engineering applied to the new urban expansions of Abu Dhabi and its urban sprawl. The study highlights that the creation of new urban Islands have multiple functions such as breakwaters that allow for the creation of new public beaches and spaces of gathering in the living city/archipelago, and act as an integral part of architectural branding, by changing the image of the city from a transit city to one that aims to become part of the global city network similar to Singapore, Hong Kong and Kuala Lumpur etc. Abu Dhabi's urban islands such as Al-Reem, Al-Maryah, Al-Saadiyat and Yas Island represent major investment opportunities in the construction and real estate sector. The State sponsored infrastructure and emerging mega museums and cultural hubs transformed Islands that were primarily desert and marshlands to urban enclaves. Such investments had to be protected from coastal erosion created by waves and tidal changes through the construction of water barriers and breakwater protection systems. Abu Dhabi's 2030 Vision is beginning to materialize to the community as new urban morphologies and iconic buildings rebrand the image of Abu Dhabi. The urban island development represents an alternative solution to that of Dubai's Palm Islands that can only be appreciated from above/aerial views and were constructed artificially by backfilling parts of Dubai's waterfront. Abu Dhabi's new Islands were reshaped to conceal the breakwaters that protect the main archipelago and create new epic-centers and pedestrian promenades along the series of water canals and estuaries. Abu Dhabi's urban expansion that is part of the 2030 Vision manifests and clear sense of comprehensive planning that includes investment in infrastructure in order to support the new spaces of public gathering, culture and leisure.

\section{References}

[1] P. Gupta, Futures, fakes and discourses of the gigantic and miniature in 'The World' islands, Dubai, Island Studies J., 10(2), 181-196 (2015)

[2] K. Zhang and S. Leatherman, Barrier Island population along the U.S. Atlantic and Gulf Coasts, J. of Coastal Research, 27(2), 356-363 (2011)

[3] D. Ponzini, Large scale development projects and star architecture in the absence of democratic politics: The case of Abu Dhabi, UAE, Cities, 28, 251-259 (2011)

[4] G. Evans, Hard-branding the cultural city from Prado to Prada, Int. J. of Urban and Regional Research, 27(2), 417- 440 (2003)

[5] Oxford Business Group, The Report: UAE: Abu Dhabi 2015, Oxford Business Group London, (2015)

[6] A. Gospodini, Portraying, classifying and understanding the emerging landscapes in the post-industrial city, Cities, 23(5), 311-330 (2006) 
[7] A. Grydehøj, Constructing a center on the periphery: urbanization and urban design in the island city of Nuuk, Greenland, Island Studies J., 9(2), 205-222 (2014)

[8] A.D. King, Spaces of global cultures: Architecture, urbanism, identity, New York, Routledge, (2004)

[9] Z. Demirbilek, V.G. Panchang, CGWAVE: A coastal surface-water wave model of the mild-slope equation, Technical Report CHL-98-26 (US Army Engineer Waterways Experiment Station, Vicksburg, Mississippi, (1998)

[10] US Army Corps of Engineers, Coastal engineering manual, Report No. EM 1110-21100, US Army Engineers Waterways Experiment Station, Vicksburg, Mississippi, (1995)

[11] B. Xu, V.G. Panchang, Z. Demirbilek, Exterior reflection in elliptic harbor wave models, J. of Waterway, Port, Coastal, an Ocean Engineeing, 122, 118-126 (1996) 